http://jmscr.igmpublication.org/home/ ISSN (e)-2347-176x ISSN (p) 2455-0450

crossref DOI: https://dx.doi.org/10.18535/jmscr/v7i9.82

Journal Of Medical Science And Clinical Research

\title{
A Comparative Analysis between Epidural Ropivacaine and Dexmedetomidine versus Ropivacaine and Clonidine for the control of Post Operative Pain in Lumbar Spine Surgery: A Randomised Control Trial
}

\author{
Authors \\ Dr Amartya Das ${ }^{1}$, Dr Chiranjib Bhattacharyya ${ }^{2 *}$ \\ ${ }^{1}$ Consultant Anaesthesiologist, GNRC Community Hospital, Barasat \\ ${ }^{2}$ Associate Professor of Anaesthesiology, Institute of Post Graduate Medical Education \& Research, Kolkata \\ *Corresponding Author \\ Dr Chiranjib Bhattacharyya \\ Address- Block- HA 280, Sector 3, Salt lake, Kolkata-700097, India
}

\begin{abstract}
Background: Without a proper post operative analgesic plan, patients undergoing elective lumbar spine surgeries suffer from acute post operative pain and tend to develop chronic low back pain syndromes. A prospective randomised study was done to compare the analgesic profile of dexmedetomidine and clonidine as adjuvants to ropivacaine, when used via epidural route.

Methods: Forty four subjects, 24 male and 20 female, 20-65 years, belonging to American Society of Anaesthesiologists Physical Status I and II, who underwent elective lumbar spine surgery were randomly divided into 2 groups, ropivacaine + clonidine (group C) and ropivacaine + dexmedetomidine (group D). At the end of the surgery, an epidural catheter was placed by the surgeon under direct vision. Group $C$ received $20 \mathrm{ml} 0.2 \%$ ropivacaine $+2 \mu \mathrm{g} / \mathrm{kg}$ clonidine and group D received $20 \mathrm{ml} 0.2 \%$ ropivacaine $+1 \mu \mathrm{g} / \mathrm{kg}$ dexmedetomidine through the catheter. Onset of analgesia, time to peak effect, duration of analgesia, haemodynamic parameters and side effects were noted.

Results: Patients of group D had faster onset, early peak effect, prolonged duration of analgesia and better haemodynamic stability. The incidence of nausea, vomiting, respiratory depression, dry mouth, motor block were comparable in both groups, but sedation scores were higher in group D.

Conclusion: Epidural analgesia with ropivacaine and alpha 2 adrenergic agonists provided safe and reliable pain relief in lumbar spine surgery in early post operative period. Dexmedetomidine as an adjuvant, was associated with better analgesic parameters, safe haemodynamics and less side effects compared to clonidine.
\end{abstract}

\section{Introduction}

Lumbar Spine surgeries with a dorsal or ventrodorsal approach are notorious for severity of post operative pain, increased morbidity and incidence of complications and prolonged postoperative rehabilitation. In addition, unrelieved postoperative pain itself is a risk factor for development of chronic pain syndromes ${ }^{(1,2)}$. Sources of pain after spinal surgery include the skin incision, healing muscle tissue with reactive spasm, dural and nerve root inflammation, the site of bony excision of vertebra and graft donor site, 
and internal fixation devices reacting with overlying tissue ${ }^{(3)}$. Postoperative pain therapy mainly consists of parenteral or oral opioids in combination with non-steroidal-anti-inflammatory agents, but it often results in insufficient pain control and side effects such as respiratory depression, nausea, and vomiting.

Epidural analgesia have been shown to be superior to intravenous analgesia with respect to quality of pain control, incidence of adverse effects and pulmonary, cardiac, and gastrointestinal dysfunction $^{(4,5)}$. Local anaesthetic agents have been used successfully through epidural route for the control of postoperative pain. Alpha 2 adrenergic agonists are being increasingly used as adjuvants for prolongation of duration of analgesia. A prospective randomised double blinded study was done to compare the efficacy and safety of two $\alpha 2$ adrenergic agonists, clonidine and dexmedetomidine as adjuvants along with ropivacaine $0.2 \%$, administered by the epidural route for post operative analgesia after lumbar spine surgeries.

\section{Procedure}

The study was done after getting approval from the Institutional Medical Ethics committee (Memo No. Inst/IEC/2015/235) and obtaining written informed consent from all patients. A total of 44 patients belonging to American Society of Anaesthesiologists Physical Status (ASA PS) class I and II, aged between 20-65 yrs, belonging to either sex, who had undergone elective lumber spine surgery under general anaesthesia were selected for the study. The nature of surgeries included laminectomy \pm discectomy for prolapse of intervertebral disc, fixation and instrumentation for fracture of spine and vertebral bodies etc . Patients with pre operative motor weakness and new onset immediate post operative motor weakness were excluded from the study.

Patients were familiarized with the Visual Analogue Scale (VAS) and also with the type of questions they were going to face after the end of the surgery regarding the intensity of their pain.
Patients were given alprazolam $0.5 \mathrm{mg}$ on the night before the surgery. On the day of surgery, patients received ranitidine $150 \mathrm{mg}$ orally with a sip of water $2 \mathrm{hrs}$ before surgery. In the operation theatre, after obtaining intravenous (IV) access via a $18 \mathrm{G}$ canula, standard monitoring devices- noninvasive blood pressure (NIBP), pulse oxymeter, electrocardiograph (ECG) leads were attached and the baseline parameters were recorded. A standard technique of general anaesthesia was followed in every case.

After completion of the surgical procedure and before wound closure, a 19 gauge epidural catheter was placed in the epidural space under direct vision through a separate skin puncture just above the surgical incision with a 17 gauge Touhy's needle, by the surgeon. To maintain uniformity the catheter was positioned caudally into the epidural space at a distance of upto $8 \mathrm{cms}$ from the skin. After properly securing the catheter in place the surgical wound was closed. Subcutaneous skin tunneling was done for catheter fixation. The patients were made supine and extubated after adequate reversal from neuromuscular blockade.

Patients were shifted to post-anaesthesia care unit (PACU) and vital parameters were continuously monitored. Once they complained of pain (Visual analogue scale or VAS > 4) the study was started.

A test dose of $3 \mathrm{ml}$ of Lignocaine with adrenaline $(1: 2,00,000)$ was injected through the epidural catheter after negative aspiration of blood or CSF and patients were randomly allocated to one of the two groups in a double blinded fashion on a computer generated code.

Group C $(\mathrm{n}=22)$ - received $20 \mathrm{ml}$ ropivacaine $0.2 \%$ and clonidine $2 \mu \mathrm{g} / \mathrm{kg}$ body weight (ampoule contains $150 \mu \mathrm{g} / \mathrm{ml}$ ). Total test drug solution was made $21 \mathrm{ml}$ after dilution with normal saline.

Group D $(\mathrm{n}=22)$ - received $20 \mathrm{ml}$ ropivacaine $0.2 \%$ and dexmedetomidine $1 \mu \mathrm{g} / \mathrm{kg}$ body weight (ampoule contains $100 \mu \mathrm{g} / \mathrm{ml}$ ). Total test drug solution was made $21 \mathrm{ml}$ after dilution with normal saline. 
An anaesthesiologist who was not a member of the anaesthetic team, prepared and administered the appropriate study drugs in the PACU. He/she remained unaware of the nature of the study and was not involved in further data collection and analysis.

After administration of the study drugs through the epidural catheter, the following parameters were noted by an independent observer.

a) Pain score by using VAS every 5 mins for 30 mins and then every 30 mins until the need for additional analgesic.

b) Onset of analgesia in minutes (VAS $<4$ after epidural drug administration).

c) Time required to attain peak level of analgesia in minutes (achieving VAS score 0 )

d) Duration of analgesia in minutes (starting from initial epidural drug administration to once the patient asks for additional analgesia with VAS>4)

e) Monitoring of vital parameters such as NIBP, pulse rate every 30 mins.

f) Side effects such as nausea, vomiting, respiratory depression, motor blockade (Bromage scale >1), deep sedation (Ramsay sedation scale >3), shivering, bradycardia and hypotension.

g) Evidence of infection of the surgical site such as redness, oedema, purulent discharge from the wound, in the first 3 days post op.

Once the patients asked for additional analgesia (VAS $>4$ ) for pain relief, the study was ended.

Hypotension (more than 20\% reduction of MAP) was treated with injection mephentermin 3-6 mg IV. Bradycardia (Heart rate $<50$ beats/min) was treated with injection atropine $10 \mu \mathrm{g} / \mathrm{kg}$ body weight.

Nausea and vomiting was treated with injection ondansetron $0.1 \mathrm{mg} / \mathrm{kg}$ body weight. Shivering was treated with injection tramadol $50 \mathrm{mg}$ IV.

\section{Sample Size Calculation and Statistical Analysis}

Sample size for the study was calculated on the basis of duration of analgesia as the primary outcome measure. It was calculated that 21 subjects would be required per group in order to detect a difference of 45 mins in this parameter with $90 \%$ power \& 5\% probability of Type I error. This calculation assumes standard deviation of 45 mins for the duration of analgesia and 2 sided testing. Sample size was calculated by nMaster 2.0 software (Department of Biostatistics, CMC, Vellore).

Data was summarised by routine descriptive statistics namely Mean \& Standard Deviation for numerical variables and counts \& percentage ( \% ) for categorical variables. Numerical variables was compared between groups by Students' independent samples 't-test' if normally distributed or by Mann-Whitney ' $U$ ' test if otherwise. Chi-square test or Fisher's exact test was employed for intergroup comparison of categorical variables. Analysis done was 2 tailed $\& \mathrm{p}<0.05$ was considered statistically significant.

\section{Results}

Of the 44 patients selected for the study, 1 patient was excluded because before administration of the test dose ,on aspiration blood mixed fliud came upto the filter of the epidural catheter assembly. 1 patient was excluded due to accidental dural injury during surgery.

The demographic profile of the patients of both group $\mathrm{C}$ and group $\mathrm{D}$ was comparable with regards to age, sex, height, weight, ASA PS class and is demonstrated below.(Table 1) 


\section{JMSCR VoI||07||Issue||09||Page 476-485||September}

Table 1: Demographic profile and other parameters of Group C and Group D

\begin{tabular}{|l|c|c|c|}
\hline $\begin{array}{l}\text { Demographic and other } \\
\text { parameters }\end{array}$ & $\begin{array}{c}\text { Group C } \\
\text { Mean } \pm \text { SD }\end{array}$ & $\begin{array}{c}\text { Group D } \\
\text { Mean } \pm \text { SD }\end{array}$ & P value \\
\hline Age (years) & $39.45 \pm 11.99$ & $39.76 \pm 13.29$ & 0.9369 \\
\hline Sex (M/F) & $12 / 9$ & $11 / 10$ & 1.0000 \\
\hline Height $(\mathrm{cm})$ & $162.3 \pm 9.65$ & $163.0 \pm 10.20$ & 0.8169 \\
\hline Weight (kg) & $70.68 \pm 12.0$ & $67.55 \pm 12.45$ & 0.4054 \\
\hline Duration of surgery (mins) & $79.82 \pm 25.52$ & $86.71 \pm 27.42$ & 0.3980 \\
\hline ASA PS (I/II) & $13 / 8$ & $11 / 10$ & 0.7557 \\
\hline
\end{tabular}

ASA PS-American Society of Anaesthesiologists physical status./ Group C- Ropivacaine + Clonidine / Group D- Ropivacine +Dexmedetomidine / SD - Standard deviation.

Onset of analgesia was earlier in Group D (6.921 \pm 1.36 mins $)$ as compared to the Group C (8.152 \pm $0.92 \mathrm{mins})$ which was statistically significant. (p $=0.0011$ )

Duration of analgesia in patients of Group D (385.6 \pm 27.04 mins) were prolonged when compared with the Group C (333.7 \pm 21.62 mins $)$, and this was statistically significant. $(\mathbf{p}<\mathbf{0 . 0 0 0 1})$
The addition of dexmedetomidine shortened the time taken (12.09 \pm 1.44 mins $)$ to reach peak analgesic effect (VAS $=0$ ) and was statistically significant ( $\mathbf{p = 0 . 0 1 0 6 )}$ when compared with addition of clonidine (13.78 \pm 1.64 mins). (Table 2)

The patients of the Group D were found to have a better analgesic profile than the Group C.

Table 2: Analgesic characteristics of group C and group D

\begin{tabular}{|l|c|c|c|}
\hline Analgesic Characteristics & $\begin{array}{c}\text { Group C } \\
\text { Mean } \pm \text { SD }\end{array}$ & $\begin{array}{c}\text { Group D } \\
\text { Mean } \pm \text { SD }\end{array}$ & P value \\
\hline Onset of analgesia (min) & $8.152 \pm 0.92$ & $6.921 \pm 1.36$ & 0.0011 \\
\hline Time to peak effect (min) & $13.78 \pm 1.64$ & $12.09 \pm 1.44$ & 0.0106 \\
\hline Duration of analgesia (min) & $333.7 \pm 21.62$ & $385.6 \pm 27.04$ & $<0.0001$ \\
\hline
\end{tabular}

In both groups VAS scores showed a significant decreasing trend in the first 15 mins post injection. However the mean VAS score were higher in group $\mathrm{C}$ as compared to group $\mathrm{D}$ patients indicating a better pain control. The patients were pain free from 20 mins to 210 mins as evidenced by $\mathrm{VAS}=0$. Hereby VAS scores started to rise and when the patients asked for additional analgesic and VAS $>4$, the study was ended.

\section{VAS Group C vs Group D (first 30 mins)}

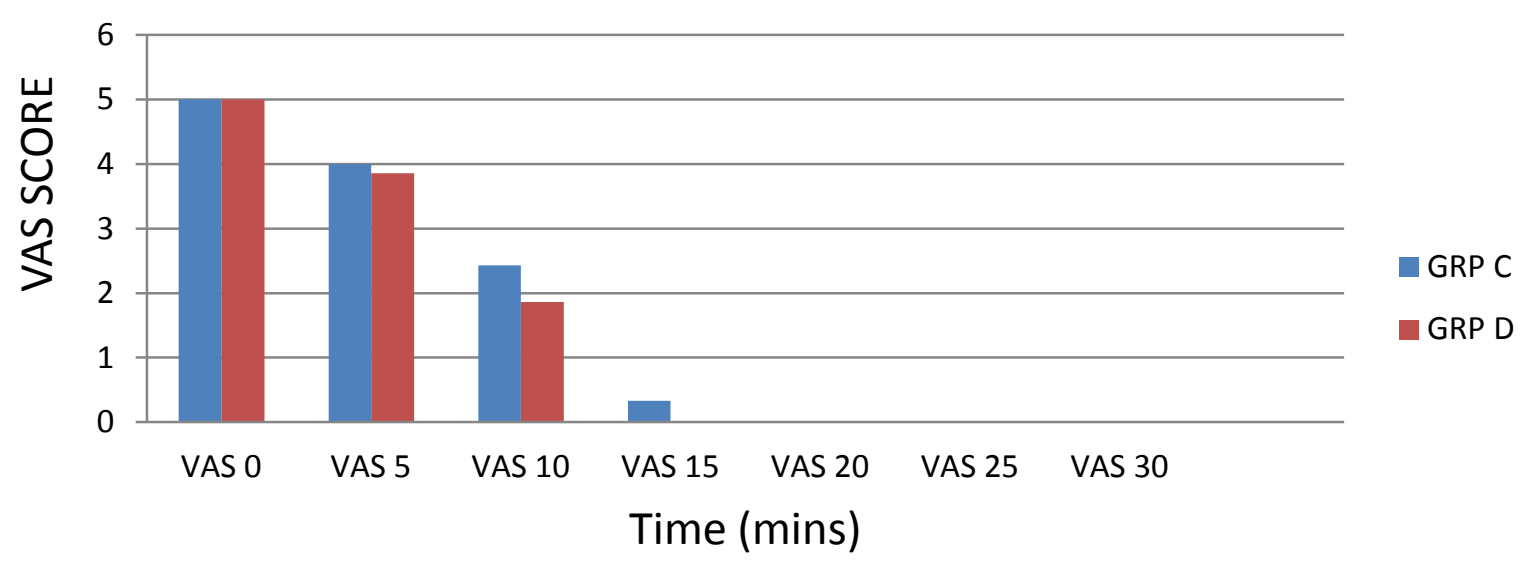

Figure 1: Comparison of VAS scores between Group C and group D during first 30 mins 
VAS Group C vs Group D (30-450 mins)

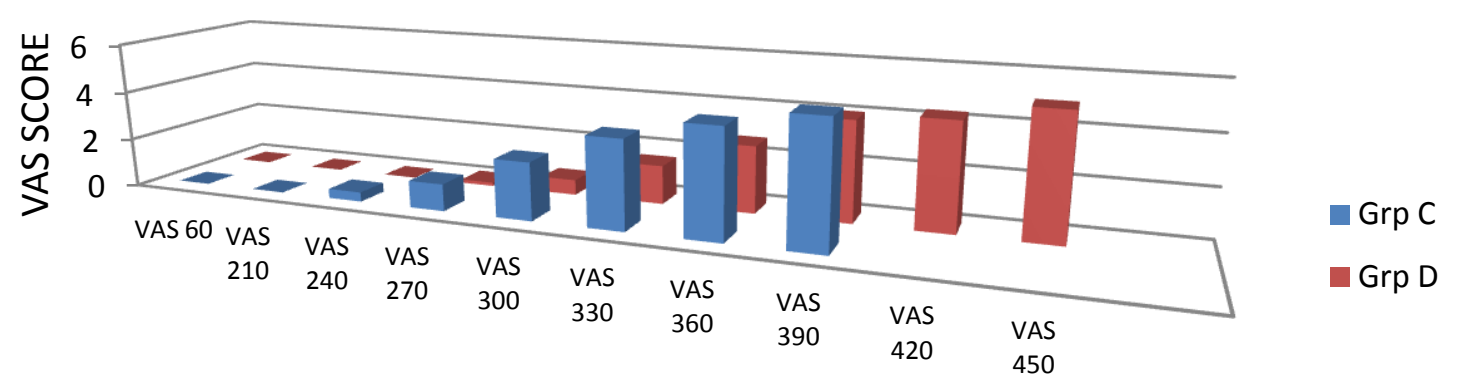

Time (mins)

Figure 2: Comparison of VAS scores between group C and group D (30-450 mins)

Heart rate, systolic blood pressure, diastolic blood pressure and mean arterial pressure, all started decreasing after the administration of the study drugs. Between 60 mins and 210 mins there was significant decrease in heart rate in Group $\mathrm{C}$ as compared to the Group D, but none of the patients required any interventions for the reduced heart rate.

Table 3: Comparison of mean heart rate (HR) between group C and group D (60-210 mins)

\begin{tabular}{|l|c|c|c|}
\hline & $\begin{array}{c}\text { Group C } \\
\text { Mean } \pm \text { SD } \\
\text { HR (beats/min) }\end{array}$ & $\begin{array}{c}\text { Group D } \\
\text { Mean } \pm \text { SD } \\
\text { HR (beats/min) }\end{array}$ & P value \\
\hline 60 mins & 67.15 .33 & 72.67 .124 & 0.0096 \\
\hline $90 \mathrm{mins}$ & 62.54 .95 & 70.87 .01 & $<0.0001$ \\
\hline $120 \mathrm{mins}$ & 61.94 .83 & 68.525 .5 & 0.0002 \\
\hline $150 \mathrm{mins}$ & 61.574 .97 & 67.524 .67 & 0.0003 \\
\hline $180 \mathrm{mins}$ & 61.575 .01 & 65.954 .18 & 0.0038 \\
\hline $210 \mathrm{mins}$ & 61.245 .26 & 64.714 .076 & 0.0215 \\
\hline
\end{tabular}

Except this change in heart rate, all the other haemodynamic parameters were comparable and nonsignificant between the two groups.

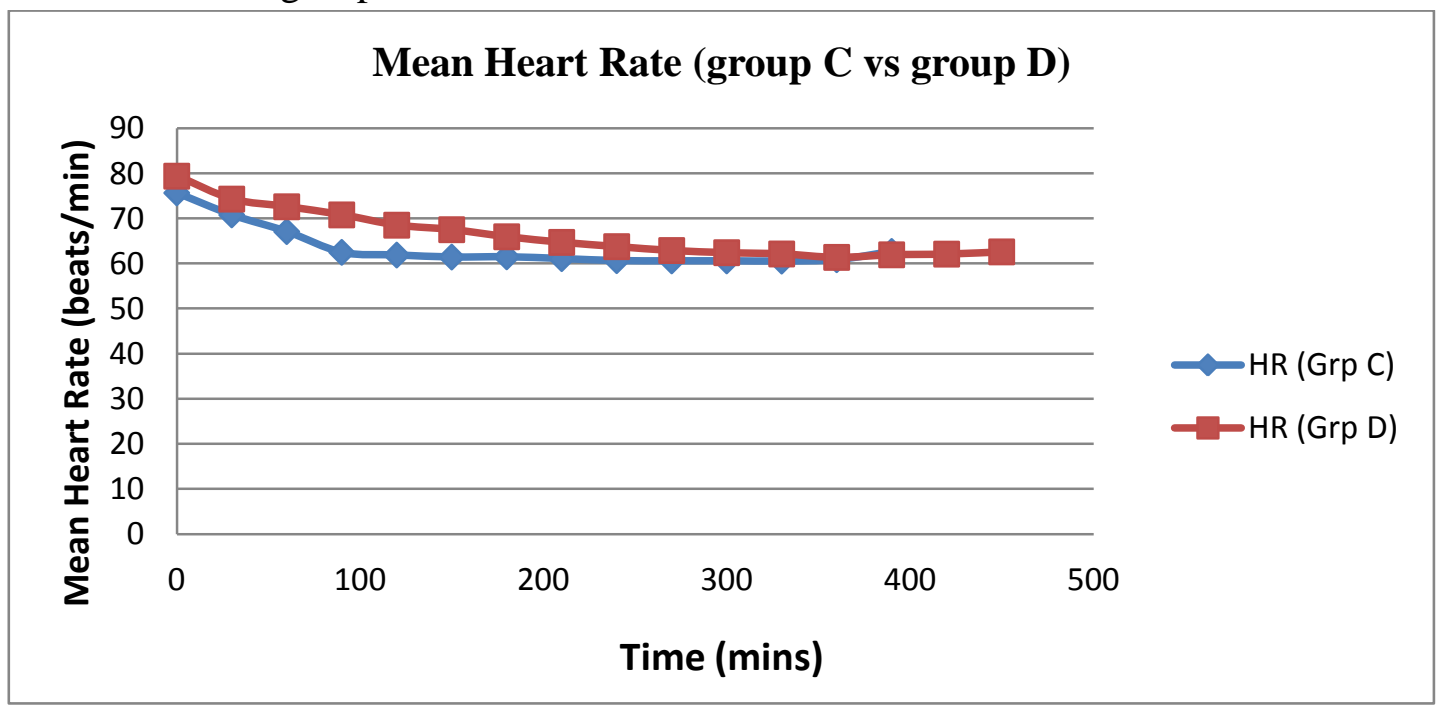

Figure 3 : Comparison of Mean Heart Rate between Group C and Group D 


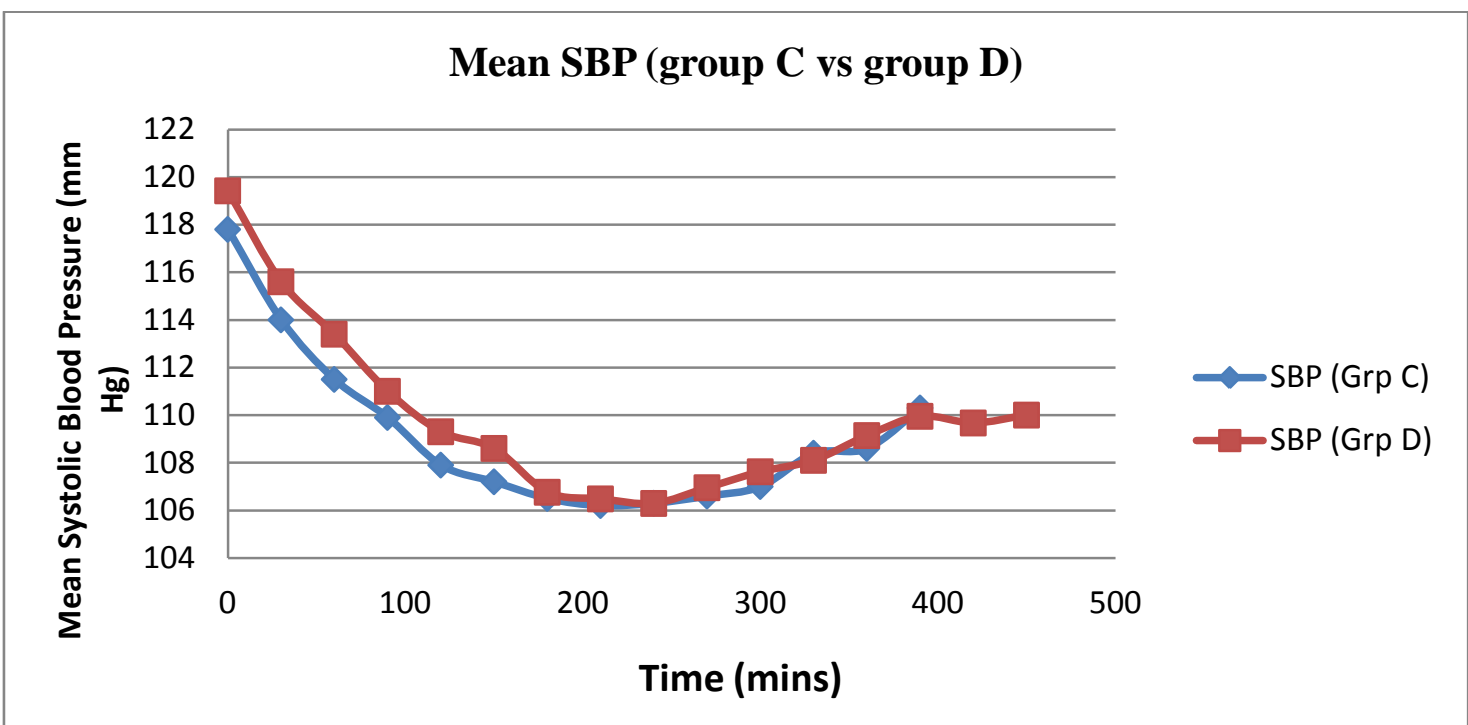

Figure 4: Comparison of Mean Systolic Blood Pressure between Group C and Group D

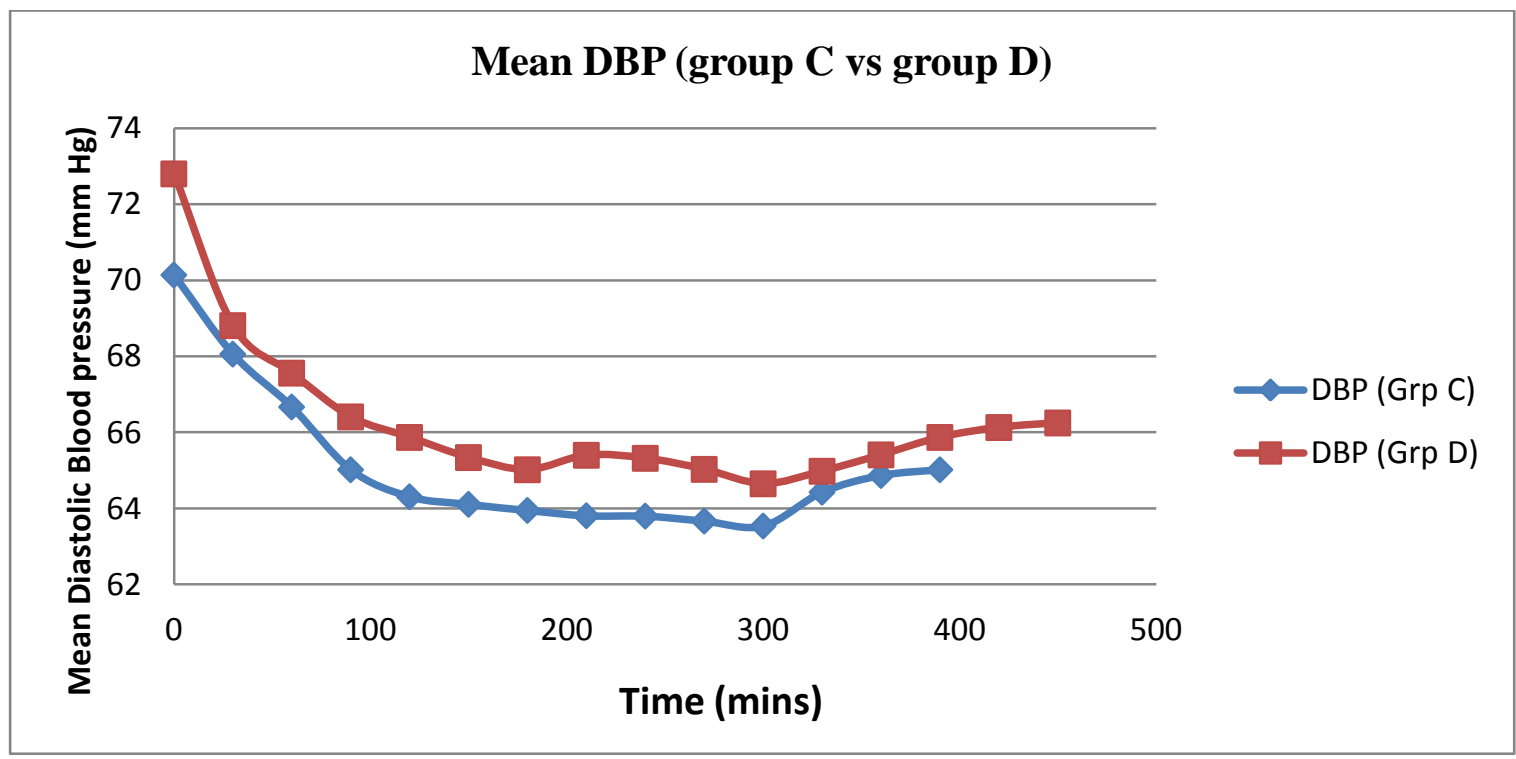

Figure 5: Comparison of mean Diastolic Blood pressure between Group C and Group D

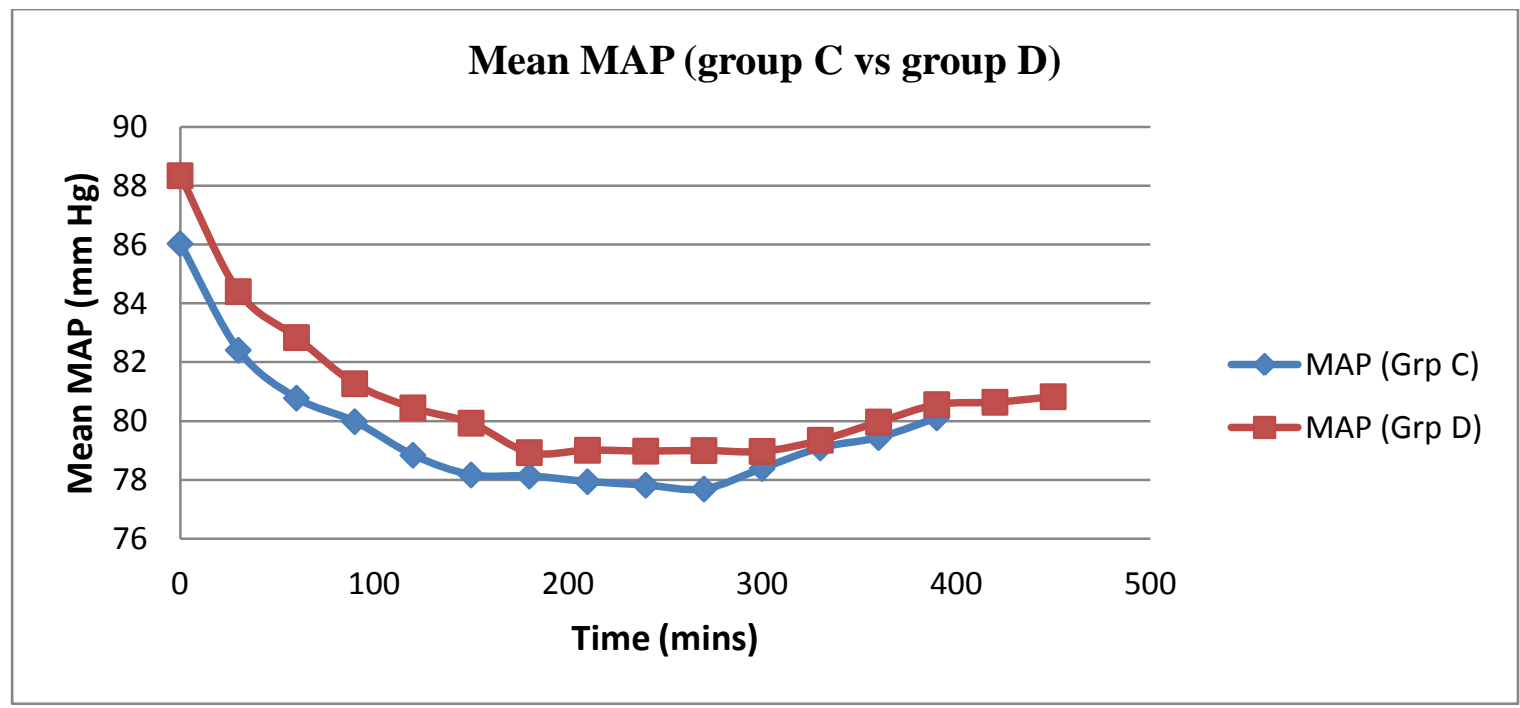

Figure 6: Comparison of mean Mean Arterial Pressure between Group C and Group D 
Various side effects were also compared in the post-injection period. The incidence of dry mouth was comparable and statistically non-significant in both groups, but there were sedation scores (Ramsay Sedation Scale) of 3 and 4 in both groups which was clinically relevant. On comparison, patients of group D showed higher sedation scores (RSS) than group C. Other side effects such as nausea, vomiting, shivering, headache were found to be statistically non significant. None of the patients showed respiratory depression or motor block in either group $^{(6)}$.

Patients were followed up in the post operative period for 3 days under collaboration with Neurosurgery dept. for any evidence of post surgical infection of the wound as manifested by redness, oedema, excessive collection in the suction drain. None of the patients showed any evidence of post surgical infection.

\section{Discussion}

The use of regional anaesthesia techniques for post operative analgesia still remains controversial in patients undergoing lumbar spine surgery under general anaesthesia. However the benefits of regional anaesthesia regarding acute post surgical pain control and better recovery and rehabilitation cannot be matched by conventional analgesic techniques like parenteral opioids, NSAIDS. Nevertheless, employment of regional analgesia for post operative pain relief after lumbar spine surgery is much restricted due to its high cost, lower acceptance by surgeons for fear of impaired wound healing, wound infection and inability to check the motor power at regular intervals. An epidural catheter can be placed before, during or after the surgery by the surgeon himself for pain relief. The most commonly used drugs via epidural route are long acting local anaesthetics with or without opioids (morphine, fentanyl and its analogues, etc).

The main aim of this study is to compare the analgesic profile and side effects of clonidine and dexmedetomidine as adjuvants to ropivacaine, used via epidural route for post operative analgesia.

Alpha 2 agonists, clonidine and dexmedetomidine were chosen in this study to decrease the total consumption of opioids and opioid related side effects like PONV and respiratory depression which are difficult to manage in the neurosurgical ward ${ }^{(7)}$.

Clonidine is a common and inexpensive drug which is used as an adjuvant with local anaesthetics in various regional and neuraxial techniques. Bajwa et al showed that when ropivacaine is combined with clonidine $(2 \mu \mathrm{g} / \mathrm{kg})$ and administered via epidural route, the analgesic parameters are similar to that of dexmedetomidine. But in this study ropivacaine was used in much higher concentration of $0.75 \%$. Clonidine via epidural route, when used in doses much larger than $2 \mu \mathrm{g} / \mathrm{kg}$ do not offer any significantly better pain control but causes refractory hypotension and bradycardia and severe sedation.

Dexmedetomidine is a new addition to the class of alpha-2 agonist which has got numerous beneficial effects when used through epidural route $^{(8)}$. It acts on both pre and post synaptic sympathetic nerve terminal and central nervous system thereby decreasing the sympathetic outfow and nor-epinephrine release causing sedative, anxiolytic, analgesic, sympatholytic and haemodynamic effects.

Dexmedetomidine does cause a manageable hypotension and bradycardia but the striking feature of this drug is the lack of opioid-related side effects like respiratory depression, pruritis, nausea, and vomiting.

Intraoperative activation of epidural was not done to allow the neurosurgeons to check for improvement in motor and sensory function immediately after the operation.

In this study VAS score was used to delineate the severity of pain and the quality of analgesia at a certain point of time. The study drugs were administered epiduraly in the PACU when the VAS score was $>4$. 
Many a time for achieving desired peri-operative analgesic effect, invariably large volumes of local anaesthetics are used, thereby increasing the possibilities of local anaesthetic toxicity and deleterious haemodynamic consequences.

Studies are going on with newer local anaesthetics like ropivacaine and levobupivacaine. The new amide local anaesthetic Ropivacaine has minimal cardio-vascular and central nervous system toxicity as well as a lesser propensity of motor block during post-operative epidural analgesia. ${ }^{(9,10)}$

Babu et al ${ }^{(11)}$ compared the effects of epidural ropivacaine with dexmedetomidine and ropivacaine with clonidine for post operative analgesia in spine surgeries. They included a wide variety of patients ranging from PIVD, spine tumours, spine fracture, scoliosis correction, etc. Sixty subjects were randomly allocated into 2 groups receiving either $20 \mathrm{ml} 0.2 \%$ ropivacaine and $1 \mu \mathrm{g} / \mathrm{kg}$ dexmedetomidine (RD group) and $20 \mathrm{ml} 0.2 \%$ ropivacaine and $2 \mu \mathrm{g} / \mathrm{kg}$ clonidine (RC group) via epidural catheter. Onset of analgesia, time to peak effect, duration of analgesia, cardiorespiratory parameters, sideeffects and need of rescue intravenous (IV) analgesics were observed .Group RD had earlier onset and earlier peak analgesic effect, more prolonged duration of analgesia and greater stability of cardiorespiratory parameters when compared with group RC. None of the patients needed rescue analgesics in either group. The side- effects profile was also comparable. The authors concluded that epidural route provided acceptable analgesia in spine surgeries and avoided the need of IV analgesics. Dexmedetomidine is a better neuraxial adjuvant compared with clonidine for providing early onset and prolonged post-operative analgesia and stable cardiorespiratory parameters.

Bajwa SJ et al ${ }^{(8)}$ in 2011, compared the efficacy and clinical profile of two $\alpha-2$ adrenergic agonists, dexmedetomidine and clonidine, in epidural anaesthesia in patients undergoing vaginal hysterectomy. The patients were divided into 2 groups: Group RD received $17 \mathrm{ml}$ of $0.75 \%$ epidural ropivacaine and $1.5 \mu \mathrm{g} / \mathrm{kg}$ of dexmedetomidine, while group $\mathrm{RC}$ received admixture of $17 \mathrm{ml}$ of $0.75 \%$ ropivacaine and 2 $\mu \mathrm{g} / \mathrm{kg}$ of clonidine. The initial and post-operative block characteristics and cardio-respiratory parameters were comparable and statistically nonsignificant, however the sedation scores with dexmedetomidine were significantly better than clonidine. The authors concluded that dexmedetomidine is a better neuraxial adjuvant compared to clonidine for providing early onset of sensory analgesia, adequate sedation and a prolonged post-operative analgesia in patients undergoing vaginal hysterectomy.

Zaric et $\mathrm{al}^{(9)}$ compared the effects of $0.1 \%, 0.2 \%$, $0.3 \%$ ropivacaine with $0.25 \%$ bupivacaine . Motor block was minimal with $0.1 \%$ ropivacaine, so that all subjects could be mobilized; it was moderate with 0.2 and $0.3 \%$ ropivacaine and most intense with $0.25 \%$ bupivacaine. Hence ropivacaine was chosen for this study.

Epidural ropivacaine has been used in previous studies in higher concentrations of $0.75 \%{ }^{(8,12)}$. Lower concentration $(0.2 \%)$ of the drug was chosen to avoid motor blockade and haemodynamic instability. After spinal surgery, any motor blockade due to epidural analgesia should be strictly avoided because postoperative hematoma with the development of paralysis due to compression of the spinal cord or cauda equina syndrome may not be detected.

Gottschalk et al ${ }^{(13)}$ used $0.1 \%$ ropivacaine via epidural route and got significantly lower VAS scores but continuous infusions were used in that case. This low concentration of ropivacaine was chosen to avoid any kind of motor blockade in the lower extremities.

Blumenthal et $\mathrm{al}^{(14)}$ used $0.3 \%$ ropivacaine via epidural route in scoliosis correction surgery and found excellent analgesic parameters as well as reduced motor blockade, but they used a double epidural catheter technique.

The patients belonging to the dexmedetomidine group showed better analgesic profile in terms of 
onset of analgesia, time taken to reach peak effect, and total duration of analgesia ${ }^{(8,15)}$ and these findings were statistically significant. This probably can be explained by the greater affinity of dexmedetomidine to alpha 2 adrenergic receptors than clonidine ( 8 times) ${ }^{(16)}$.

The limitations of this study are comparatively low sample size as the study population is restricted to patients undergoing lumbar spine surgery only and inadequate period of post operative follow up upto 3 days to detect any evidence of post surgical infection. Corrective surgery for spinal deformities were very infrequently done, so this set of patients could not be included in this study.

Results of the present study corroborates, reinforces and adds evidence to the studies that showed epidural analgesics significantly reduce post surgical pain in spine surgeries and reduces the requirement of rescue analgesics. ${ }^{(17,18)}$

Placing a catheter in the epidural space of a patient undergoing spine surgery is not devoid of risks. There are chances of infection leading to formation of an epidural haematoma, epidural abscess and surgical site infection. Rigorous vigilance and frequent monitoring of the patient is mandatory to detect early evidences of development of such complications, especially if post operative anti thrombotic therapy is initiated to prevent deep vein thrombosis.

Further research needs to be carried out on a much larger group of patients to determine the actual incidence of catheter related post operative infective complications. More studies need to be done to assess the efficacy of epidural analgesia on all levels of spinal surgeries.Optimum dose of the adjuvant added to the epidural local anaesthetics needs to be determined by carrying out similar studies using different doses of the adjuvant drugs.

\section{Conclusion}

From the findings of the present study it may be concluded that dexmedetomidine may be a more effective adjuvant to epidurally administered ropivacaine $0.2 \%$ compared with clonidine for providing post operative analgesia for lumbar spine surgeries.

Conflict of Interest- Nothing to declare.

\section{Acknowledgement}

This article could not have seen the light of day without the efforts of many contributors. I wish to convey my thanks to Dr.Sarbari Swaika for her constant encouragement and guidance and to Prof. Abhijit Hazra for his meticulous and detailed instructions regarding the statistical calculations.

Source of Funding- Nothing to declare. The study was conducted in a govt. hospital and all the necessary equipments and study drugs were provided free.

\section{References}

1. Sandkuehler J. Fear the pain. Lancet 2002; 360:426.

2. Perkins FM, Kehlet H. Chronic pain as an outcome of surgery: A review of predictive factors. Anesthesiology 2000; 93:1123-33.

3. Smith GF. Perioperative care of the spine patient. In: White AH, Schofferman JA, editors. Spine care.St Louis :Mosby ;1995.

4. Rodgers A, Walker N, Schug S, McKee A, Kehlet H, Van Zundert A, et al . Reduction of postoperative mortality and morbidity with epidural or spinal anaesthesia: Results from an overview of randomized trials. BMJ 2000; 231:1493-7

5. Liu S, Carpenter RL, Neal JM. Epidural anesthesia and analgesia: Their role in postoperative outcome. Anesthesiology 1995; 82:1474-506

6. Kanazi GE, Aouad MT, Jabbour-Khoury SI, Al Jazzar MD, Alameddine MM, AlYaman R, et al. Effect of low-dose dexmedetomidine or clonidine on the characteristics of bupivacaine spinal block. Acta Anaesthesiol Scand 2006;50:222-7.

7. Farmery AD,Wilson-MacDonald J.The analgesic effect of epidural clonidine 
after spinal surgery : A randomized placebo-controlled trial. Anaesth Analg 2009;108:631-4.

8. Bajwa SJ, Bajwa SK,Kaur J,Singh G,Arora V,Gupta S ,Kulshrestha A,Singh A, Parmer SS, Singh A, Goraya SPS. Dexmedetomidine and clonidine in epidural anaesthesia: A comparative evaluation. Indian $\mathrm{J}$ Anaesthesia 2011;55:116-21.

9. Zaric D, Nydahl PA, Philipson L, Samuelsson L, Heierson A, Axelsson K. The effect of continuous lumbar epidural infusion of ropivacaine $(0.1 \%, 0.2 \%$, and $0.3 \%$ ) and $0.25 \%$ bupivacaine on sensory and motor block in volunteers: A doubleblind study. Reg Anesth 1996;21:14-25.

10. McClellan KJ, Faulds D. Ropivacaine: An update of its use in regional anesthesia. Drugs 2000;60:1065-93.

11. Saravana Babu MS, Verma AK, Agarwal A, Tyagi CM, Upadhyay M, Tripathi S.A comparative study in the post operative spine surgeries : Epidural ropivacaine with dexmedetomidine and ropivacaine with clonidine for postoperative analgesia. Indian $\mathbf{J}$ Anaesth 2013;57:371-6.

12. Bajwa SJ, Arora V, Kaur J, Singh A, Parmar SS. Comparative evaluation of dexmedetomidine and fentanyl for epidural analgesia in lower limb orthopedic surgeries. Saudi J Anaesth 2011;5:365-70.

13. Gottschalk A, Freitag M, Tank S, Burmeister MA, Kreil S, Kothe R. Quality of postoperative pain using an intraoperatively placed epidural catheter after major lumbar spinal surgery. Anesthesiology. 2004 Jul;101(1):175-80.
14. Blumenthal S,Min K, Nadig M, Borgeat A. Double Epidural Catheter with Ropivacaine versus Intravenous Morphine: A Comparison for PostoperativeAnalgesia after Scoliosis Correction Surgery. Anesthesiology 2005; 102:175-80.

15. Antônio Mauro Vieira, Taylor Brandão Schnaider, Antônio Carlos Aguiar Brandão, Flávio Aparecido Pereira, Everaldo Donizeti Costa, Carlos Eduardo Povoa Fonseca : Epidural clonidine or dexmedetomine for post-cholecystectomy analgesia and sedation. Rev Bras Anestesiol, 2004 Aug;54(4):473-8.

16. Aryan HE, Box KW, Ibrahim D, Desiraju U,Ames CP. Safety and efficacy of dexmedetomidine in neurosurgical patients. Brain Inj 2006;20:791-8.

17. Kumar RJ, Menon KV, Ranjith TC. Use of epidural analgesia for pain management after major spinal surgery. J Orthop Surg (Hong Kong) 2003;11:67-72.

18. Rechtine GR, Love LC. The postoperative laminectomy pain control using bupivacaine and epidural morphine. $\mathrm{Br} \mathrm{J}$ Anaesth 2005;95:59-68. 